public health authorities through the columns of your journal, I am sure visitors would be benefited.

I am, Sir, yours faithfully,

H. S. BURNELL-JONES.

Tower Gardens-road, Tottenham, N., July 7th, 1908.

\section{THE TECHNIQUE OF OPSONIC ESTIMATION.}

\section{To the Editor of THE LANCET.}

SIR,-The method of estimating the resistance of a patient's blood to infection in use in this laboratory presents certain advantages over the ordinary procedure and hence we beg to submit it to your readers. (1) A truer estimate of the antibacterial powers of the blood is obtained as the individual's serum and leucocytes are both examined; (2) the procedure is more simple and rapid, as the patient's leucocytes, which are freely obtained in the preparation, are used; the tedious collection of washed lencocytes is saved; (3) by varying the dilution of the serum and by use of a thick emulsion of bacteria a truer estimate of the quantity of opsonin is obtained (W. E. Marshall); and (4) the staining qualities of the preparation are excellent and the addition of sodium citrate solution does not practically affect the results, as shown also by Dr. R. M'L. Veitch.

Methnd.-One large volume of the patient's blood is taken up into the capillary pipette, then five equal volumes of citrated salt solution (sod. cit. 1.5 per cent., sod. chlor. 0.75 per cent.) and one equal volume of thick bacterial emulsion in salt solution $(0.75$ per cent. $)$. This is well mixed and sealed and a similar preparation of a "normal" blood is made and both incubated in the horizontal position in the incubator at $37^{\circ} \mathrm{C}$. for 20 minutes.

Three slides of each are prepared and stained and 50 leucocytes counted in the usual way, the bacteria per lencocyte of the control slide is taken as unity; the methods in use in estimating resistance to infection are : (1) the wellknown one of Sir A. E. Wright, Professor W. B. Leishman, and Captain Douglas in which the phagocytes are regarded as indifferent factors. (2) The procedure of dilution (Simon, Klien, \&c.) based upon numbers of leucocytes capable of phagocytosis ("phagocyting leucocytes") in varying dilutions of the serum. Dr. C. E. Simon states that the phagocytic power generally diminishes with the dilution, but it may be rapidly exhausted. In the latter case Simon assumes that the amount of opsonin is materially less, the use of a concentrated serum might show an apparently normal opsonic serum content for a given number of organisms which would be inadequate for a larger number. Such inadequacy becomes manifest when the serum is diluted, a rapid exhaustion of phagocytic power occurring. Dr. G. Dean regards this method as affording some check upon the opsonic index as obtained by Wright's technique. The leucocytes are regarded, again, as indifferent. For some years workers in Brighton saw that the index of a patient's resistance would be bound to be more representative if his or her leucocytes were used. It was simple to prove that cosinophiles and myelocytes have less powers of phagocytosis than polymorphonuclears, and that the polynuclear leucocytes of workers in this laboratory were possessed of a threefold phagocytic power to those of a myelocythæmic patient. Dr. J. C. G. Ledingham showed this independently and that the opposite condition held in the polynuclears of a patient with chronic lymphatic leukæmia.

Rosenow showed that pneumonic leucocytes are more active per se than normal ones. Opie emphasises the necessity of leucocytic digestion as compared with mere ingestion of bacteria and demonstrated the powers of digestion on gelatin of leucocytes removed from serum. Glynn confirms the variation in the functional activity of leucocytes and Shattock and Dudgeon in a recent valuable paper clearly show the importance of estimating the "hæmophagocytic" powers, including both leucocytes and serum. In our experience the functional activity may be diminished or increased in immunes, and as we believe that it comes within the unavoidable margin of error of the present technique we have not so far been able to detect the factors that guide it. This we hope to do.

We are, Sir, yours faithfully,

F. G. Bushnelt.

Sussex County Hospital, July 10th, 1908.

A. G. Troup.

\section{A LURID STORY.}

To the Editor of THE LANCET.

Sin,-The following story has several morals, the most obvious perhaps being the need for a proper system of nurses' registration and for the inspection of nursing homes and institutions.

Early this year a lady applied for admission as a nurse at a general hospital but as she was 34 years of age she was. considered too old to be engaged for the full period of four years' training. As in all other respects she seemed very suitable the matron consented to take her on trial for three months as a paying probationer. She obtained a medical certificate stating that she was in good health and gave two references, one from a lady who said she had known her for about 12 years and in whose family she had at different times done some nursing ; the other from the superintendent of a suburban nursing home, under whom she had worked for the previous three months. Both ladies spoke very highly of her. Both the applicant and her referees had to answer printed inquiries about her previous health and the diseases from which she had suffered and said nothing whatever about any mental disorder. For about two months she did her work quite satisfactorily as a junior probationer in the hospital, when suddenly she developed symptoms of acute mania, addressed a postcard to the King, became incoherent, and had all kinds of delusions, religious, sexual, \&c. Her nearest relation, a married sister living many miles away, was at once informed of the circumstances. She evidently telegraphed to a private asylum, from which $\mathbf{a}$ nurse was promptly sent, provided with an Urgency Order under the Lunacy Act, and as soon as this had been filled up at the hospital the patient was removed to the asylum. From this nurse it was ascertained that the patient had been under treatment in the same asylum on either four or five previous occasions and that the last attack had been a very severe one, so that she had been detained about 12 months, and had only been discharged about a year ago.

Inquiries were now made from the matron of the nursing home who had been one of the patient's referees. She acknowledged that when she engaged her, being rather pressed at the time for nurses and satisfied with the applicant's appearance and address, she had accepted her without any references whatever, that she had nursed some patients in the institution and others in their own homes, and had given complete satisfaction. Thus we have an instance of a woman being taken on to the staff of a nursing home without having had any hospital training whatsoever and without any inquiries being made. She is then placed in charge of patients, sometimes at their own homes, presumably as a fully trained nurse, yet she had not long been discharged for the fourth or fifth time from an asylum and was liable at any moment to a fresh attack of acute mania.

As it happened, when the recurrence did occur no particular harm was caused, but had the nurse been in a private house in sole charge of a patient seriously ill instead of being merely a junior probationer in a hospital the consequences might have been very different.

July 13th, 1908.

I am, Sir, yours faithfully, F.R.C.P.

Royal College of Surgeons in Ireland.The following prizes were awarded for the summer session :Barker anatomical prize $(£ 31$ 10s.): G. C. Sneyd; special prize £26 5s., Miss I. M. Clarke. Carmichael scholarship (£15): J. S. Pegum. Mayne Scholarship (£8): T. C. Boyd. Gold medal in operative surgery : R. Adams; silver medals, C. Greer and G. C. Sneyd. Stoney memorial gold medal in anatomy : H. G. P. Armitage. Practical histology : J. T. Duncan, first prize (£2) and medal ; and L. W. Roberts, second prize (£1) and certificate. Practical chemistry: B. Kelly, first prize (£2) and medal ; and W. N. Harrison, second price (£1) and certificate. Public health and forensic medicine: F. W. Warren, first prize (£2) and medal; and H. R. Tighe, second prize (£1) and certificate. Materia medica: J. S. Pegum, first prize (£2) and medal ; and Miss N. Williams, second prize (£1) and certificate. Biology: M. J. Hillery, first prize (£2) and medal; and G. E. Pepper, second prize (£1) and certificate. The winter session will commence on Thursclay, Oct. 15th. 